\title{
Private incentives for the emergence of co-production of offshore wind energy and mussel aquaculture
}

\author{
Robert Griffin $^{\mathrm{a}, *}$, Bela Buck ${ }^{\mathrm{b}}$, Gesche Krause ${ }^{\mathrm{b}}$ \\ a The Natural Capital Project, Woods Institute for the Environment, Stanford University, 371 Serra Mall, Stanford, CA 94305, USA \\ ${ }^{\mathrm{b}}$ Alfred Wegener Institute for Polar and Marine Research, Am Handelshafen 12, 27550 Bremerhaven, Germany
}

\section{A R T I C L E I N F O}

\section{Article history:}

Received 4 March 2014

Received in revised form 12 July 2014

Accepted 24 October 2014

Available online 5 November 2014

\section{Keywords:}

Coproduction

Wind energy

Mussels

Marine spatial planning

\begin{abstract}
A B S T R A C T
Technological solutions to increase the efficiency of spatial use can play a key role as part of the toolbox of marine spatial planning. Co-locating of multiple ocean uses can potentially increase the production and enjoyment of the ocean while limiting impacts. However, a basic precondition for co-locating or coproduction is that all parties' private incentives are aligned. We use a case study of co-locating an offshore wind energy firm and a mussel aquaculture firm to assess the incentive structure for cooperation and to demonstrate that social benefits from co-locating exist. We find that there is room for cooperation between firms based on potential cost sharing and that the demonstrated social benefits may arise without government intervention.
\end{abstract}

(C) 2014 Elsevier B.V. All rights reserved.

\section{Introduction}

The efficient use of marine resources is becoming increasingly important as many coastal systems have reached their capacity limits and offshore areas are increasingly utilized (Buck et al., 2008). Marine spatial planning efforts in Europe and, more recently, the U.S. are seeking to rationalize the use of coastal areas and lay the groundwork for comprehensive resource use plans (European Commission, 2011; Olsen et al., 2014). At the same time, coordinated research efforts are developing formal methods and tools to assess spatial tradeoffs in marine ecosystem services (Douvere, 2008; Hoagland et al, 2003; Kareiva et al., 2011; Tallis et al., 2011). All of this effort seeks to find ways to improve governance and inform the allocation of resources among diverse stakeholders for sustainable long term solutions that best use limited marine resources.

The increasing and often conflicting use of marine resources has not only driven the development of improved governance protocol, but also research into technological solutions that seek to fit more activity into a given area. For example, Stoutenburg and Jacobson (2011) assess the viability of incorporating wave energy devices into offshore wind farms. Their results indicate that such a farm would reduce the variability of power generation as well as reduce transmission costs per megawatt of capacity. Co-locating this energy infrastructure also reduces the overall footprint and increases the power generating density of the farm, resulting in a more efficient use of offshore space. This is an example

\footnotetext{
* Corresponding author. Tel.: +1 401855 4367; fax: +1 6507251783.

E-mail addresses: rmgriff@stanford.edu (R. Griffin),Bela.H.Buck@awi.de (B. Buck), Gesche.Krause@awi.de (G. Krause).
}

of a technological solution where a single firm could implement both technologies at a single site, thereby increasing their earnings without necessarily expanding their footprint. However, coastal waters typically feature a host of stakeholders with divergent interests and overlapping resource use who may find coordination difficult (Krause et al., 2011). Since more efficient use of offshore space increases social welfare by providing more with less impact, it is a desirable policy goal and should be fostered where possible. The open question remains, however: to what extent are cooperative solutions possible when different stakeholder groups need to come together?

Wind energy and aquaculture compete for space with other uses in many coastal locations and each industry is developing rapidly (Fig. 1). To assess the potential of co-locating for marine spatial planning in the context of different coastal resource user groups, this paper draws on a hypothetical co-use setting based in the North Sea of Germany. It models the cooperative production ("coproduction") of wind energy and blue mussel farming (Mytilus edulis) and analyzes the incentive structure for cooperation. ${ }^{1}$ We employ new data and a componentlevel wind energy model that allow us to assess the net present value of different wind farm configurations. In Germany, wind energy is subsidized using feed-in tariffs and transmission asset subsidies reflecting a societal preference for establishing offshore renewable energy. We examine the extent to which the transmission asset subsidy influences the net present value of an offshore wind facility in order to assess the

\footnotetext{
${ }^{1}$ Other potential co-uses have been established on decommissioned oil platforms in the Gulf of Mexico, which are today used for private fishing (Heitt and Milon, 2002), or aquaculture purposes such as finfish farming (Chambers, 1998; Kaiser et al., 2010, 2011; Midget, 1994; Wilson and Stanley, 1998).
} 


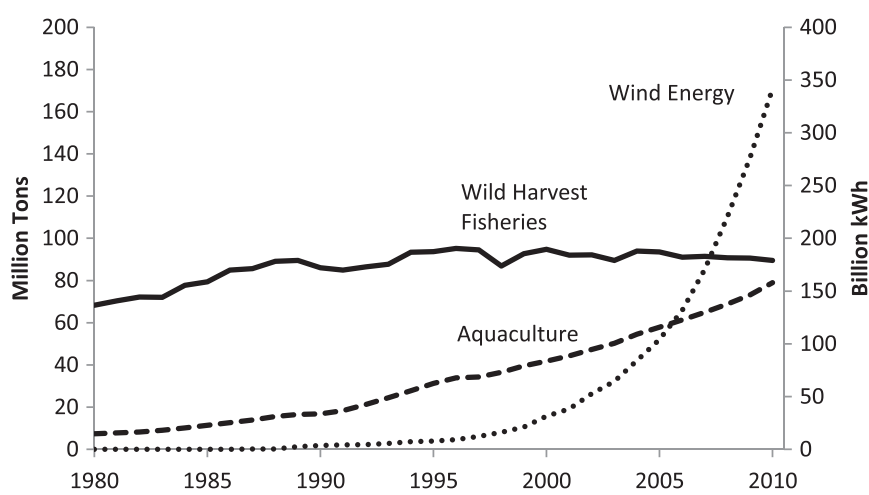

Fig. 1. The progression of renewable energy worldwide recently has coincided with a similar increase in marine aquaculture. Source: U.S. EIA and FAO.

viability of offshore wind energy and coproduction in locations without this policy. Next, we explore the spatial and value efficiency gains from coproduction to make the case that it produces socially desirable outcomes. Finally, we address the incentive structure for collaboration between offshore wind firms and aquaculture firms. Several questions are addressed here: does the relative scale of the two firms inhibit the likelihood of cooperation; what is the extent of possible cost sharing that could occur between firms; and finally, what are the potential financial downsides to collaboration?

\section{Methods}

\subsection{Study area}

To examine the potential for coproduction, we detail a hypothetical co-located offshore wind energy and blue mussel (Mytilus edulis) culturing facility near the site of the planned Nordergründe wind farm in the German North Sea. The case study site is 17 nautical miles from the coastal port of Bremerhaven (Fig. 2) in water depths of 10 to 15 meters. These are favorable conditions for producing wind energy, but are further offshore and in heavier seas than aquaculture has traditionally been conducted (Buck et al, 2010). However, Buck et al. (2004, 2008) and Buck and Krause (2012) make the case that incorporating aquaculture into offshore wind farms is theoretically possible for at least some types of aquaculture. Recent research efforts have gone on to show the technological feasibility of incorporating aquaculture rearing infrastructure into wind farms (Buck, 2007a; Buck and Buchholz, 2004) and find favorable growing conditions for sugar kelp, mussels, and oysters in high energy seas (Buck, 2007b; Buck and Buchholz,

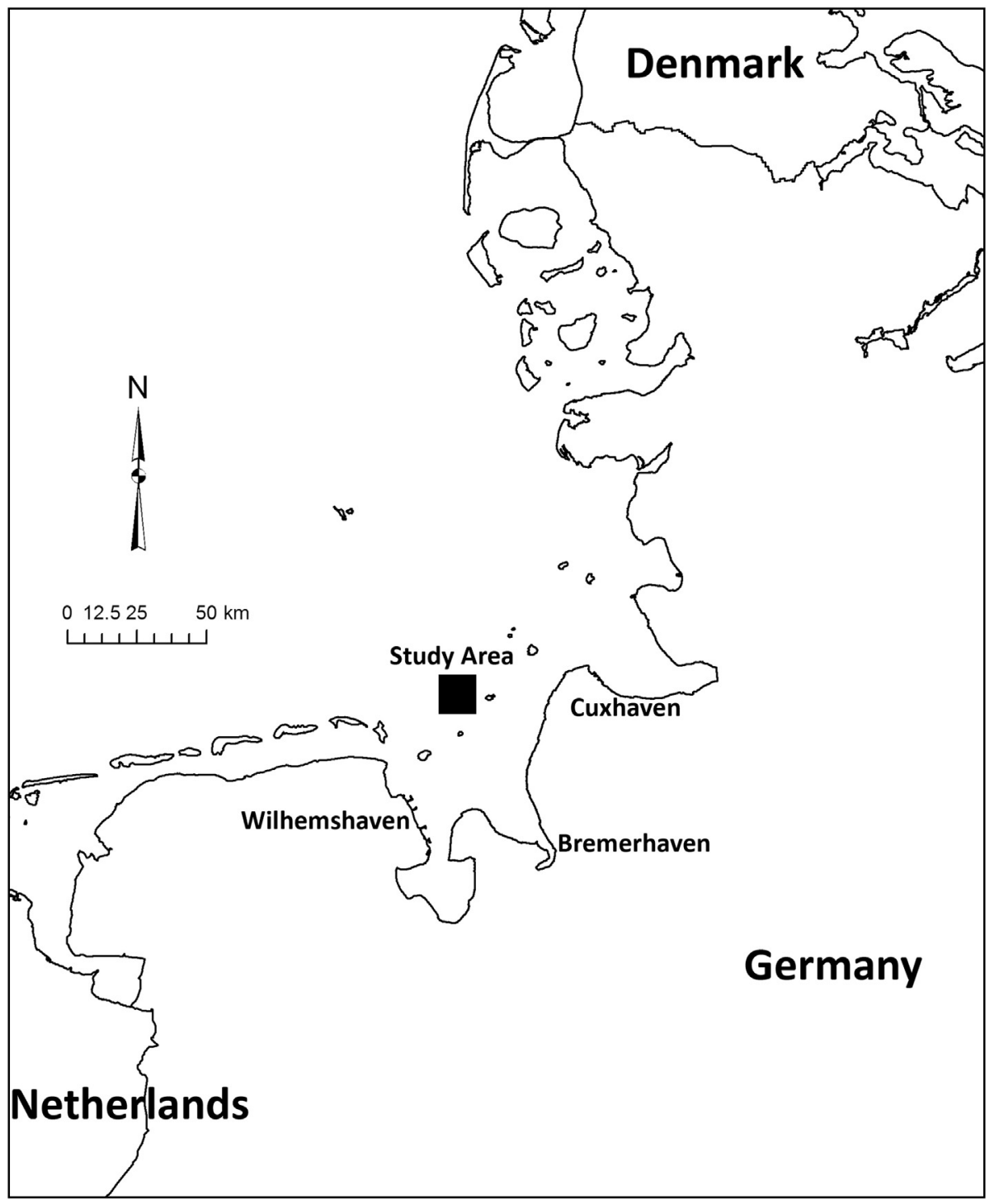

Fig. 2. Study area. 
2005; Pogoda et al., 2011, 2012, 2013). These low maintenance extractive species are attractive candidates due to their low costs, a key consideration because offshore aquaculture and wind energy are capital intensive endeavors with high costs and plenty of risk (Klinger and Naylor, 2012; Weaver, 2012).

Germany provides a good case study for marine spatial planning as it is a highly developed economy with significant marine activity but relatively limited offshore space. Areas close to shore are dominated by shipping interests, wild harvest fisheries, as well as conservation, leaving little room for aquaculture or wind energy (BSH, 2009). Existing near shore mussel aquaculture is under continual pressure from competing interests, and any new aquaculture farms face a choice between the few marginal near-shore areas still available or moving offshore. Germany has announced plans to eliminate nuclear power generation as part of their energy portfolio by 2022 (Jorant, 2011), and as part of this plan has enacted significant support for offshore wind energy under the Renewable Energy Sources Act. However, the densely utilized nearshore area has lead the vast majority of planned and installed wind energy farms in Germany to locate in the German Exclusive Economic Zone (EEZ), which extends beyond 12 nautical miles from shore (Buck et al, 2008). As the process of moving offshore unfolds across different sectors, an efficient planning process would look to fit more activity into the nearshore area while also preparing for offshore expansion by fostering integrated siting in advance of conflicts. Finally, while Germany is facing marine spatial conflicts in the near-term, these problems are not unique to Germany. Use conflicts and high coastal land values in countries with significantly more offshore space have pushed wind and aquaculture further offshore or onto the land (Cicin-Sain et al., 2005).

\subsection{Economic analysis}

To understand the incentives for cooperation, we model the production and financial structure of the co-located firms and assess their potential gains and losses from cooperation. To illustrate each firm's private earnings from production, we employ a discounted cash flow analysis, with a focus on cost categories with potential savings due to coproduction. Discounted cash flow analysis considers the timing of costs and revenues over the lifetime of a project and estimates the present value of the stream of cash flows. This is the standard method used for assessing the financial viability of a project and comparing merits of alternate project designs (Yescombe, 2002). We model two different site scales that reflect common wind farm configurations (Table 1), as well as modeling the effect of removing German subsidies on electrical transmission equipment so our results can generalize to other wind energy locations with favorable blue mussel culturing prospects.

While every attempt has been made to use appropriate functional relationships and data calibrated to the North Sea context, this modeling predicts the financial state of hypothetical future facilities in a context of considerable uncertainty. There are no aquaculture firms currently

Table 1

Scale scenarios for a co-located farm.

\begin{tabular}{lcc}
\hline & $18 \times 5.0 \mathrm{MW}$ & $80 \times 3.6 \mathrm{MW}$ \\
\hline Wind Farm & & \\
Turbines & 18 & 80 \\
$\quad$ Number of turbines & 5.0 & 3.6 \\
$\quad$ Rating (MW) & 90.0 & 288.0 \\
Total capacity (MW) & Jacketed & Monopile \\
Foundations & 18.8 & 67.7 \\
Infield cable $(\mathrm{km})$ & 11.0 & \\
Farm area $\left(\mathrm{km}^{2}\right)$ & & \\
& & 16.0 \\
Aquaculture & 4 & 136 \\
Plots & 284 & \\
$\quad$ Number & 4 & \\
Longlines & & \\
Farm area $\left(\mathrm{km}^{2}\right)$ & &
\end{tabular}

operating in the German EEZ and there are 5 wind farms operating in German offshore waters that all were built in the last 4 years. This considerable project uncertainty in both industries drives investors to demand higher returns for high risk. As such, for both industries we use a high weighted average cost of capital as suggested by Levitt et al. (2011) for offshore wind energy to capture the high risk of these projects. All values throughout are given in pre-tax 2012 EUR.

Since data regarding many key parameters are subject to considerable uncertainty, we employ Monte Carlo simulation to provide additional information about the likely distribution of outcomes. Monte Carlo simulation establishes a representative distribution for a given parameter by transforming limited discrete data samples into continuous distributions that best capture the range and frequency of likely values. Using those distributions as inputs into the discounted cash flow analysis model, the researcher draws random values for each uncertain parameter and these are processed through the model to calculate outputs. This process repeats a large number of times to create a distribution of potential outcomes, thereby providing information not only on the most likely outcome, but also key information about the range and likelihood of other potential outcomes. Stochastic project risk modeling has considerable precedent in project finance (Kwak and Ingall, 2007) and specifically in wind energy and aquaculture (see for example, Munoz et al. (2009) and Valderrama and Engle (2001)).

\subsection{Wind}

Germany is vigorously supporting domestic wind energy production as a means of moving away from conventional fossil energy resources as well as nuclear power (Jorant, 2011). Generous subsidies exist for developers that guarantee favorable energy prices and reduce capital costs. One of these subsidies is a feed-in tariff for wind energy which sets a guaranteed price per kWh of energy delivered. ${ }^{2}$ Having a guaranteed price and buyer for produced energy is a critical component in reducing financial risk for developers and has been a major impediment to development elsewhere. In addition to price guarantees, Germany has mandated that the transmission system operator finances, constructs, and operates the transmission systems that connect offshore wind farms to the grid, significantly reducing capital expenditures for wind farm developers. This national-level commitment to wind energy has lead Germany to develop the third most wind energy generation capacity worldwide, behind China and the U.S. with 30,000 MW (GWEC, 2013). While this capacity is almost entirely on land, Germany is quickly moving to install more offshore capacity. Offshore wind turbines are less obtrusive than turbines on land, as their apparent size and noise is mitigated by distance (Ladenburg and Lutzeyer, 2012). Also, since water has less surface roughness than land, the average wind speed is typically higher. As of November 2014, Germany had eight offshore farms currently generating power, eight more under construction, and twenty three more approved. ${ }^{3}$

\subsubsection{Valuation approach}

Offshore wind energy is very capital intensive with front-loaded costs for generation equipment such as foundations, cables, and turbines and relatively little in the way of ongoing costs, since wind, unlike coal or gas, is a freely available source of power. Information about component costs is notoriously difficult to attain as transactions are all conducted on a contract basis and developers and suppliers have little incentive to share this information. Parameterizing a discounted cash

\footnotetext{
2 The policy that sets the feed-in tariff rates is the Renewable Energy Sources Act of 2012. The act allows for a choice of two options, an accelerated and normal feed-in tariff schedule. Developers can receive $.15 € / \mathrm{kWh}$ for 12 years or $.19 € / \mathrm{kWh}$ for 8 years. After that, the feed-in tariff is $.035 € / \mathrm{kWh}$ for the lifetime of the project. There is a possibility of extending the lifetime of the high feed-in tariff if the development occurs in waters deeper than $20 \mathrm{~m}$ or more than 12 nautical miles from shore. These tariffs are the topic of considerable debate in Germany and may be allowed to expire.

${ }^{3}$ Source www.4coffshore.com/windfarms and www.bsh.de.
} 
Table 2

Model parameters and distributions.

\begin{tabular}{|c|c|c|c|c|c|}
\hline Name & Units & Pessimistic & Expected & Optimistic & Distribution \\
\hline \multicolumn{6}{|l|}{ Energy generation } \\
\hline Wind speed & $\mathrm{m} / \mathrm{s}$ & 9.5 & 9.8 & 10 & Triangular \\
\hline Availability & $\%$ & 90 & 95 & 97 & Triangular \\
\hline Energy losses & $\%$ & 23 & 17 & 2 & Triangular \\
\hline \multicolumn{6}{|l|}{ Wind Finances } \\
\hline$* *$ Grid connection & $€$ mil & - & - & - & Normal (MSE = 62) \\
\hline Turbines (3.6 MW) & $€$ mil & 6.41 & 6.03 & 5.54 & Triangular \\
\hline Turbines (5.0 MW) & $€$ mil & 10.6 & 10.5 & 10.4 & Triangular \\
\hline Infield cable & $€$ mil & 0.305 & 0.185 & 0.151 & Triangular \\
\hline Monopile foundation & $€$ mil & 1.86 & 1.72 & 1.50 & Triangular \\
\hline Jacket foundation & $€$ mil & 2.06 & 1.94 & 1.82 & Triangular \\
\hline Installation & $\%$ of CAPEX & 20 & 17 & 7 & Triangular \\
\hline Miscellaneous costs & $\%$ of CAPEX & 8 & 5 & 2 & Triangular \\
\hline $\mathrm{O} \& \mathrm{M}$ & $\%$ of CAPEX & 3.5 & 3.25 & 3.0 & Triangular \\
\hline WACC & $\%$ & 13.3 & 11.6 & 9.6 & Triangular \\
\hline Decommissioning & $\%$ of CAPEX & 7.0 & 3.7 & 2.6 & Triangular \\
\hline Wind Price & $€ /$ kWh (years) & $0.15(1-12)$ & $1-20)$ & & $\mathrm{NA}$ \\
\hline \multicolumn{6}{|l|}{ Mussel Production } \\
\hline Biomass harvested & tonnes/year/4 plots & 4757 & 5946 & 7136 & Triangular \\
\hline \multicolumn{6}{|l|}{ Mussel finances } \\
\hline WACC & $\%$ & 13.3 & 11.6 & 9.6 & Triangular \\
\hline Fuel cost & $€ /$ year/vessel & 111,128 & 101,867 & 92,607 & Triangular \\
\hline Wages & EUR/year/per 4 plots & 134,831 & 132,868 & 130,904 & Triangular \\
\hline O\&M and misc costs & $\%$ of CAPEX/yr & - & 0.0375 & - & $\mathrm{NA}$ \\
\hline Infrastructure cost & EUR per 4 plots & $3,868,613$ & $3,776,503$ & $3,684,393$ & Triangular \\
\hline Vessel & EUR per 4 plots & - & $4,409,843$ & - & NA \\
\hline Licenses & EUR per 4 plots & - & 1102 & - & NA \\
\hline Land facilities & EUR per 4 plots & - & $1,653,691$ & - & NA \\
\hline Motor overhaul & EUR per vessel & - & 424,447 & - & NA \\
\hline Mussel price & $€ / \mathrm{kg}$ & - & $1.58,+.048 / \mathrm{yr}$ & - & Normal $(\mathrm{MSE}=.44)$ \\
\hline \multicolumn{6}{|l|}{ Others } \\
\hline Transmission cable & $\mathrm{km}$ & - & 27 & - & NA \\
\hline Infield cable per turbine & $\mathrm{km}$ & - & 0.91 & - & NA \\
\hline
\end{tabular}

** See Table 3 .

flow model to account for different design features exceeds the data requirements of a basic EUR/installed MW approach. To overcome this, we conducted an extensive review of press releases, reports, and articles to parameterize the component-level cost model necessary for investigating cost categories where coproduction may provide savings. These cost figures were validated anecdotally by industry contacts in the study area and also against published total capital cost figures from the industry website 4COffshore. Table 2 provides an overview of the values used to parameterize both the wind energy and mussel aquaculture models. Sources, justification, and validation for these parameters are given in the Appendix.

The cost model is principally a bottom-up type approach, where unit costs are attributed to different design features and total costs are tallied by multiplying by the number of units needed in our two design scenarios. This approach works well with turbines, foundations, and infield array cables as the technology is largely invariant to scaling. Connection to the mainland power grid is less amenable to a component-level analysis as the equipment required is significantly different as farm size and distance from shore increase. A farm with a few 3.6 MW turbines located close to shore may simply aggregate $33 \mathrm{kV}$ array cables and bring them to land where they can be transformed at a local substation for the high voltage electrical grid. Conversely, many of the large offshore farms planned in Germany and elsewhere will have 400 MW and greater capacity and will be greater than $60 \mathrm{~km}$ from the grid. To connect these farms to the grid, large offshore substations are planned that aggregate electricity from adjacent farms for export to land. Small losses in energy from inefficient transmission system design can become significant over the operating lifetime of a farm, so considerable effort is made to design appropriate transmission systems for each farm.
Developers will often use high voltage transmission systems and may also alternate between AC and DC technologies in an effort to overcome these losses, with different technologies being appropriate for a given transmission distance and farm generating capacity (Negra et al., 2006). As a result, the design may require different cable voltage ratings, transformers, converters, as well as offshore and/or onshore substations to house equipment.

Offshore wind energy capacity has been growing at rates above $30 \%$ for the last 5 years in Europe and projections have this rate continuing at least for the next few years (EWEA, 2013). While the grid connection costs in Germany are borne by the grid operator, to generalize our results to other locations where blue mussel coproduction might be feasible, but such generous subsidies may not be available, it is informative to assess the impact this subsidy has on costs. Since we are also interested in looking multiple wind farm designs, a transmission cost model that is flexible to key design features but does not require specific assumptions about design would be useful. With these considerations in mind, we estimated a functional relationship of observed transmission costs to key farm-level features using a dataset ${ }^{4}$ from the U.K. Office of the Gas and Electricity Markets (OFGEM):

$T C=f(M W, D)$

\footnotetext{
${ }^{4}$ In 2009, the Electricity Regulations (SI 2009/1340) mandated wind energy generating companies may not hold offshore wind energy transmission assets. A tender process was established to sell licenses to existing offshore transmission assets in a competitive market. As part of this process, OFGEM collected data on the value of existing offshore transmission assets for a dozen wind farms.
} 
This equation relates the transmission costs (TC) in EUR millions to the total generating capacity of a farm (MW) in megawatts and the distance of that farm from the grid (D) in kilometers. The results of the estimation are given in Table 3 . With this information we are able to predict the total installed capital cost of a variety of different farm designs at our study site by combining it with component and installation cost information. We have validated our cost estimation approach against stated project costs and have found a very strong correlation between stated and predicted results (see Appendix).

In addition to capital costs, wind farms also require maintenance throughout their lifetime. Periodic inspections and repairs are essential to maintaining turbines and preventing downtime. Given the relatively recent emergence of offshore wind farms, there is little guidance on estimating the costs associated with operations and management. Existing guidance typically takes the form of an annual cost that is a ratio of the original capital cost, or is given as a $€ / \mathrm{kWh}$ of energy generation. Both methodologies arrive at approximately the same level of expenditure, so we use the annual cost suggested by Boccard (2010) of somewhere between 3 and $3.5 \%$ of original capital expenditures. Since this is a cost category that has potential for cost sharing, we will return to this in the results section and explore in more detail.

To calculate revenue for our wind farm designs, we need information on energy prices and wind energy generation. Current feed-in tariff subsidies established by the Renewable Energy Sources Act of 2012 for wind energy in Germany pay energy producers a rate that varies over the lifespan of the farm (see footnote 2). To calculate annual wind energy generation, we use a method suggested by Masters (2004) and employed by Dvorak et al (2010) that estimates a capacity factor based on turbine and wind speed factors. The function:

$C F=.087 \times \bar{v}-\frac{P}{D^{2}}$

specifies the capacity factor as a function of average wind velocity at hub height in meters per second, $\bar{v}$, the rated capacity of a turbine in $\mathrm{kWh}, P$, and the rotor diameter in meters, $D$. This equation is based on a Rayleigh distribution of winds, a common assumption used in modeling wind turbine energy output. Compared against a more elaborate model using wind speed densities and power curves for the 3.6 MW turbine, the results are consistent and similar (within $5 \%$ of estimated output). Compared to published results for a 5.0 MW turbine, this method is within .1\% (see Appendix). This yields capacity factors near $50 \%$, which is similar to levels observed at the nearby Alpha Ventus wind farm (Alpha Ventus, 2010). The annual energy output for a given turbine is the maximum potential power output multiplied by the capacity factor; farm level output is calculated by summing over all turbines subject to assumptions regarding availability and grid losses (see Appendix). Finally, farm revenue is calculated by multiplying annual energy generation by the unit price of energy.

\subsection{Mussels}

Blue mussels are indigenous to the North Sea and North Atlantic and are important commercially as an edible food commodity. While they can be harvested in the wild, aquacultured mussels represent the vast majority of commercial production in Europe. Mussels are a form of extensive marine aquaculture in that they are highly dependent on local habitat conditions for growth and do not require significant effort to cultivate as they extract their food by filter feeding the surrounding water column. In this capacity they make an attractive candidate for offshore aquaculture as the effort required for cultivation is less than intensive aquaculture facilities like those for finfish where regular feeding and active care is required. ${ }^{5}$ Buck et al. (2008) and Buck (2007b) describe the results of 2 years of observing blue mussel growth characteristics at the site of this study. Employing longlines 6 meters below the surface with suspended collector ropes, they found that wild mussel spat settled abundantly and yielded an average of $10 \mathrm{~kg} / \mathrm{m}$ on grow out to market size (18 months). In water depths of 15 meters, mussels were suspended deep enough to avoid the destructive power of wave action and from potential collision through boat traffic and far enough off the bottom to avoid contamination from sand and other bottom hazards such as predation from adult sea stars.

\subsubsection{Valuation approach}

Blue mussels are the main commercially raised bivalves in the German North Sea and have traditionally been grown using bottomculture techniques in the near shore area. Germany's annual production of mussels is subject to considerable variation due to recruitment success and the availability of spat (Buck et al., 2010). In recent years Germany has represented around 1 percent of the total European production with 3,600 - 24,000 tonnes of production (FAO data, 20002010). Nguyen (2012) finds that mussels in Europe are generally price inflexible, meaning that a $1 \%$ increase in quantity consumed translates into a price decrease of less than $1 \%$. Unfortunately, due to the relative insignificance of German mussel production in the context of the European market, it was left out of that analysis and therefore we cannot predict prices as a function of production changes in Germany. However, the price inflexibility observed by Nguyen (2012) allows us to be more confident in assuming that the aquaculture firm can be assumed a price-taker with the relatively small changes in production (relative to the European market) simulated in this study. ${ }^{6}$ Based on this, we used FAO data from 1984 to 2012 on ex-farm mussel prices in Germany to estimate a price trend and price uncertainty over the simulated horizon (Table 2).

To illuminate a mussel aquaculture firm's incentives for coproduction with a wind energy firm, we employ the same stochastic discounted cash flow method as with wind energy and utilize parameter observations from Buck et al. (2010). It is important to note that the biological conditions found at the study site, including spat availability, local carrying capacity, and biomass growth, may not be applicable to all locations through the distribution of Mytilus edulis. See the Appendix and Buck et al (2010) for a fuller discussion of the modeling, parameter choice, assumptions, and limitations. For the purposes of this paper, the main differences from Buck et al (2010) are that we:

- Only focus on the production of consumption mussels using a new vessel (scenario 1 of Buck et al. (2010)).

\footnotetext{
5 Offshore finfish aquaculture may also benefit from collocating with wind farms. Using submerged fish pens and electric power from wind turbines for automated feeding could reduce costs enough to make the relatively more valuable finfish product commercially viable.

${ }^{6}$ Given that the simulated amounts meet or exceed historical production in Germany, it is likely that the domestic market will have to expand or product will have to be exported. Nguyen (2012) indicates that France is the most important market for mussels in Europe; however their domestic production only supplies about 60\% of demand. At 2010 production levels this suggests a shortfall of over 50,000 tons, which leaves German production with a reasonably close outlet for mussels that are not consumed domestically.
} 
Table 4

Operational schedule over the time horizon.

\begin{tabular}{|c|c|c|c|c|c|c|c|c|c|}
\hline Year & Pre1 & 1 & 2 & 3 & 4 & 5 & 6 & $\ldots$ & 20 \\
\hline Wind farm & CAPEX & Operational O\&M & $\rightarrow$ & & & & & & Decommission \\
\hline $1 / 2$ of mussel plots & CAPEX & Deployment O\&M & Harvest O\&M & O\&M & Harvest CAPEX O\&M & Deployment O\&M & Harvest O\&M & $\rightarrow$ & Decommission \\
\hline $1 / 2$ of mussel plots & NA & CAPEX & Deploy O\&M & Harvest O\&M & O\&M & Harvest CAPEX O\&M & Deployment O\&M & $\rightarrow$ & Decommission \\
\hline
\end{tabular}

- Analyze two scales of production, a smaller facility of 4 plots of mussel culturing longlines and larger facility that employs 16 plots. Based on limited offshore experience in constructing these facilities, we assume a constant marginal cost of equipment for a deep-water mussel farm similar to Kirkley (2008). ${ }^{7}$

- Use a 20 year time horizon, i.e. 5 iterations of the production cycle used in Buck et al. (2010). Table 4 shows the timing of the growing schedule for mussels with a biennial harvest schedule on two sets of asynchronously harvest plots, as well as the production schedule of the wind farm, over the projected lifetime of both facilities.

\section{Results and discussion}

\subsection{Net revenues}

The results of the discounted cash flow analysis for both firms across our scenarios are given in Table 5. The table is arranged with two main columns representing the financial conditions with and without the electrical transmission subsidy present at the study site. Addressing the German context with the transmission subsidy first, we find that the mean net present value for each firm is positive across both scales, thus meeting the most basic precondition for operation. The mean earnings for a wind farm are roughly half of that expected for each size mussel farm, but are close enough that the potential exists for meaningful interaction if payments between firms are necessary to ensure mutually-beneficial cooperation. From a social welfare perspective, colocating these facilities results in a 7-8\% increase in available space and improves the earnings in the footprint (versus a wind farm alone) by $230 \%$ for the small wind farm and $207 \%$ for the large wind farm. We also find that increasing the size of a coproduction facility increases the realized value per $\mathrm{km}^{2}$. Taken together, these results suggest that wind and mussel firms can be profitable in this context with the potential for meaningful dialog, and that offshore space can be more efficiently utilized with a coproduction facility.

U.K. offshore wind energy regulations changed in 2009 to mandate that no energy generator can own offshore energy transmission assets, which is conceptually very similar to the German transmission subsidy, so these results should readily extend to the U.K. as well. For countries where developers must build and maintain their own transmission infrastructure, we also assessed the effect of this policy on net earnings. We find that the transmission subsidy has a strong effect on net earnings and without it neither scale wind farm is worth building. These findings are subject to considerably more uncertainty than with the transmission subsidy, due to significant variation introduced via the estimated transmission cost equation. In the case that a wind farm is built under these conditions, there would be a strong incentive for cost sharing with an outside aquaculture firm or potentially exploring a vertically integrated wind and mussel farm to achieve positive net earnings.

\subsection{Potential shared costs}

To further investigate the potential cost savings from cooperation we disaggregate the above results and provide cost information for

\footnotetext{
7 When expanding from 4 to 16 plots, the constant returns to scale imply purchasing 4 times as much equipment (i.e. vessels, land facilities), or purchasing larger equipment but realizing no scale-based cost savings.
}

key categories for each firm in Table 6. For wind energy firms, the major cost category where coproduction may reduce costs is operations and management (O\&M). Over the lifetime of a project, O\&M costs account for roughly $20 \%$ of total costs in present value terms and provide an approximate upper bound on the portion of costs that could potentially be shared. Given that O\&M costs for a wind farm alone are about two-thirds the value of projected revenues from a mussel farm, it is clear that these firms would operate on two different scales. The extent to which wind farm O\&M costs could be reduced thus will be modest.

To assess these limits, a better understanding of disaggregated O\&M activities is necessary. From an operations costs perspective, wind farms engage in both management and administration, acquire insurance, and pay for safety mechanisms and monitoring equipment (Karyotakis, 2011). From a maintenance costs perspective, the major cost categories include replacement item costs, labor costs, and transportation costs. From the above categories, labor and transportation costs are the likely expenditures where cost savings might be realized.

The Dutch Offshore Wind Energy Converter project (Rademakers and Braam, 2003) looked closely into the optimization of maintenance of an 80 turbine offshore wind farm using 5.0 MW turbines. Maintenance falls into two general categories: preventative and correctional. Preventative maintenance includes minor repairs and inspections and is aimed at preventing turbine failure and subsequent lost energy generation. Correctional maintenance is focused on repairing minor and major failures and occurs shortly after the failure is detected. Preventative maintenance can typically be carried out by a relatively small personnel supply vessel, whereas corrective maintenance typically requires additional vessels equipped with cranes and perhaps even jack-up barges depending on the scale of repairs. These larger vessels are specialized for turbine repairs and at $€ 25,000$ per day are expensive to mobilize (Karyotakis, 2011). However, the smaller personnel vessel is ideally suited for transport of light equipment and crew for both the mussel and wind energy farm and may provide an opportunity for cost savings. Rademakers and Braam (2003) found that, for an 80 turbine farm, this smaller supply boat would be needed 103 days for corrective maintenance and 40 days for preventative maintenance per year. If preventative maintenance is undertaken in the summer to take advantage of relatively calm weather, and corrective maintenance occurs with equal probability throughout the year, this leaves 66 days of work in the summer and 77 days of work throughout the rest of the

Table 5

Net present value for scenarios, given in $2012 €$ millions.

\begin{tabular}{|c|c|c|c|c|}
\hline & \multicolumn{2}{|c|}{ Transmission subsidy } & \multicolumn{2}{|c|}{ No transmission subsidy } \\
\hline & $18 \times 5.0 \mathrm{MW}$ & $80 \times 3.6 \mathrm{MW}$ & $18 \times 5.0 \mathrm{MW}$ & $80 \times 3.6 \mathrm{MW}$ \\
\hline Wind NPV (€ mil) & 25.0 & 111.3 & -78.6 & -204.7 \\
\hline std. dev. & 18.5 & 82.1 & 99.1 & 132.7 \\
\hline Mussel NPV (€ mil) & 57.5 & 229.8 & 57.5 & 229.8 \\
\hline std. dev. & 8.8 & 35.2 & 8.8 & 35.2 \\
\hline $\begin{array}{l}\text { Size of wind farm } \\
\left(\mathrm{km}^{2}\right)\end{array}$ & 28 & 99 & 28 & 99 \\
\hline $\begin{array}{l}\text { Size of mussel farm } \\
\quad\left(\mathrm{km}^{2}\right)\end{array}$ & 1.96 & 7.84 & 1.96 & 7.84 \\
\hline \multicolumn{5}{|c|}{ Spatial efficiency increase (\%) } \\
\hline Area & 7.0 & 7.9 & 7.0 & 7.9 \\
\hline Value & 230.0 & 206.5 & - & - \\
\hline $\begin{array}{l}\text { Value/Area } \\
(€ \mathrm{mil} / \mathrm{km} 2 \text { ) }\end{array}$ & 2.8 & 3.2 & -0.7 & 0.2 \\
\hline
\end{tabular}


Table 6

Cost sharing potential, given in $2012 €$ millions.

\begin{tabular}{|c|c|c|c|c|}
\hline & \multicolumn{2}{|c|}{ Transmission subsidy } & \multicolumn{2}{|c|}{ No transmission subsidy } \\
\hline & $18 \times 5.0 \mathrm{MW}$ & $80 \times 3.6 \mathrm{MW}$ & $18 \times 5.0 \mathrm{MW}$ & $80 \times 3.6 \mathrm{MW}$ \\
\hline \multicolumn{5}{|l|}{ Wind farm } \\
\hline Revenue & 247.1 & $1,098.4$ & 247.1 & 1098.4 \\
\hline Total costs & 222.1 & 987.4 & 325.7 & 1303.1 \\
\hline \multicolumn{5}{|l|}{ Sharable costs } \\
\hline O\&M costs & 44.4 & 197.5 & 65.2 & 260.7 \\
\hline \multicolumn{5}{|l|}{ Mussel farm } \\
\hline Revenue & 77.5 & 309.9 & 77.5 & 309.9 \\
\hline Total costs & 20.0 & 80.1 & 20.0 & 80.1 \\
\hline \multicolumn{5}{|l|}{ Sharable costs } \\
\hline Vessel costs & 4.3 & 17.3 & 4.3 & 17.3 \\
\hline Fuel costs & 0.7 & 2.9 & 0.7 & 2.9 \\
\hline Wages & 1.0 & 4.1 & 1.0 & 4.1 \\
\hline
\end{tabular}

year. Rademakers and Braam (2003) found that an outright purchase of a supply vessel (at an annualized cost of 2.2-2.4 €million and present value of $24.4 €$ million) makes the most financial sense given mobilization delays and availability issues for hired boats. Given that there is excess capacity Sept - June that coincides with the entire maintenance schedule for the mussel farm, crew and vessel costs for the supply vessel provide a key opportunity for cost savings. This narrowing down of complementary maintenance activities for an 80 turbine farm provides more reasonable bounds of up to $24.4 €$ million in cost savings for the wind farm and $24.3 €$ million (from the sharable costs in Table 6) for the mussel farm.

The cost savings detailed above will rely on how much O\&M work can be done with excess capacity alone versus needing to expand investment to meet both firms' needs. In the event that cost savings are significantly biased towards one firm, our results suggest that there are enough net earnings for each firm under current German subsidy regimes to propose a reasonably attractive level of compensation for the ability to co-locate.

\subsection{Liability}

While the results give us cause to believe that co-locating aquaculture and wind energy offshore could be profitable and potentially cost-advantageous, there are some additional considerations that may influence the likelihood of cooperation. The largest potential issue is the disturbance of maintenance activities leading to a greater incidence of downtime and potential damage to equipment, both of which are an issue of liability. Downtime for a wind farm is very costly, at a daily cost of $€ 144,878$ or $€ 8,049$ per turbine for the $90 \mathrm{MW}$ wind farm and $€ 493,860$ or $€ 6,173$ per turbine for the 288 MW farm when the feedin tariff rate is $0.15 € / \mathrm{kWh}$. Similarly, if the mussel longlines are damaged during O\&M activities at the wind farm, up to two years of mussel growth could be impacted at a cost of millions. Insurance could cover these potential risks, though the cost of coverage may offset any gains from cooperation. By appropriately siting mussel plots at a low density and appropriate depth, there should be plenty of room to service both turbines and mussel plots without risk to equipment. Ultimately, the risks associated with co-locating these firms will need to be assessed as experience grows in both industries and via pilot studies of offshore coproduction, and at this point are not readily quantified.

\section{Conclusions}

Our analysis has established that mussel and wind farms could have financial incentives for co-locating at common wind farm scales in the North Sea. The potential for complementary maintenance activities using a supply vessel provides the basis for cost sharing between firms, though the specific savings each firm may realize depends on how savings are split and the extent to which the supply vessel needs additional equipment for carrying out both maintenance schedules. We have also justified the contention that social welfare and spatial efficiency can be increased by co-locating these operations, finding a 7-8\% increase in spatial efficiency and a 207-230\% increase in the density of value generated versus a wind farm alone. This is critically important in densely used coastal areas, such as the German North Sea, but more generally it is important for increasing coastal resource use while limiting the impact of coastal development on the surrounding ecosystem.

Without a significant legacy in offshore zones around the world, wind energy is in a unique position to foster cooperation with other stakeholders. While this new entrant position allows wind energy firms the opportunity to shape their relations with other ocean users, it also means that there is an inherent lack of understanding between aquaculture and wind energy. The core of each business is different enough that the skills and expertise needed varies considerably, which itself may serve to preclude cooperation. Also, the findings here apply only to culturing Mytilus edulis; other extensive species such as seaweed will face significantly different market and cost conditions, and intensive species such as finfish would require completely rethinking how the firms interact from a technical perspective.

Here we have framed the potential effects of coproduction in the context of economic considerations; however, social and regulatory issues will also play a significant role in fostering or hindering collaboration (Christie et al, 2014). Given the significant volume of subsidies already used to promote wind energy and smarter use of offshore resources, relatively modest technical or financial support for coproduction could provide the catalyst to more fully scope this idea and hopefully move the focus of marine spatial planning a little closer to collaborative solutions.

\section{Acknowledgements}

This project was supported in part by NSF IGERT grant DGE-0504103 to the University of Rhode Island Coastal Institute and in part by the Gordon and Betty Moore Foundation. The authors wish to thank Peter Kareiva and Tim Boucher for commenting on and reviewing an earlier draft of the paper. The authors would also like express gratitude for the helpful comments of an anonymous reviewer.

\section{Appendix A}

\section{A.1. Wind energy}

EWEA (2009, p. 49) has an extensive discussion on how to calculate annual power generation. They note that the key is to know the mean wind speed at hub height; the statistical distribution of wind speeds around the mean wind speed plays a minor role in determining annual wind production. Sawyer (2008) puts the average wind speed in the Nordergründe area at $8-9 \mathrm{~m} / \mathrm{s}$ as estimated by the Global Wind Energy Council. 4COffshore.com puts the mean observed wind speed at $100 \mathrm{~m}$ height from 2000 to 2009 as 9.95 m/s. Data collected at the FINO 1 observation site suggest the measurement of $9.9 \mathrm{~m} / \mathrm{s}$ is a good estimate for this area at $100 \mathrm{~m}$ height. ${ }^{8}$ Since this data has been collected for a decade, the long term variation is unlikely to be large. Based on a typical Weibull profile of wind speeds we might expect $9.5 \mathrm{~m} / \mathrm{s}-10 \mathrm{~m} / \mathrm{s}$. Information about site conditions are not detailed enough (and it has been shown to be overkill to use anything besides mean wind speeds anyway) to create exceedance probabilities.

The Carbon Trust (2008, p. 40) cites a load factor of 36\% expected for Kentish Flats, and a range of 25-36\% for three Vestas 3.0 wind farms. See pg. 108 for a breakdown of load factors and CAPEX/MW costs over a variety of wind speeds, depths, and distances from shore. EWEA (2009) defines the capacity factor of a wind turbine as the amount of

\footnotetext{
${ }^{8}$ http://www.dewi.de/dewi/fileadmin/pdf/publications/Magazin_28/12.pdf.
} 
energy delivered during a year divided by the maximum power output that turbine could have generated. EWEA (2009) states that interannual wind energy production from a turbine varies with a standard deviation of around $10 \%$ of mean energy.

Masters (2004) and Dvorak et al (2010) estimate a capacity factor based on turbine and wind speed factors. The function is based on a Rayleigh distribution of winds, a common assumption used in modeling wind turbine energy output. Compared against a more elaborate model using wind speed densities and power curves for the 3.6 MW Siemens turbine, the results are consistent and similar (within $5 \%$ of estimated output, Table A1). Compared to REPower's published results, this method is within $.1 \% .^{9}$ This yields capacity factors near $50 \%$, similar to nearby Alpha Ventus wind farm.

Table A1

Wind energy calculations and comparison of calculation methods

\begin{tabular}{lll}
\hline Mean Wind Energy Parameters & & \\
\hline & Siemens 3.6 MW & REpower 5.0 MW \\
\hline Wind speed (m/s) & 9.8 & 9.8 \\
Max power (MWh) & 31,558 & 43,830 \\
Capacity factor & 0.53816 & 0.53766 \\
Actual power (CF Method - MWh) & 16,983 & 23,566 \\
Availability & 0.95 & 0.95 \\
Pre loss total (MWh) & 16,134 & 22,387 \\
Losses (\%) & $17 \%$ & $17 \%$ \\
Net energy total (MWh) & 13,391 & 18,581 \\
Turbines & 80 & 80 \\
Farm total (MWh) & $1,071,294$ & $1,486,518$ \\
Actual power (Power curve - MWh) & 16,868 & 24,090 \\
Diff from CF method (\%) & $0.68 \%$ & $-2.10 \%$ \\
\hline
\end{tabular}

Carbon Trust (2008) assumes that availability falls over the lifetime of a wind farm, and with distance from shore. The Carbon Trust (2008, pg. 40) has expected availability for an offshore wind farm to theoretically be between 90 and 95\%. Offshore Design Engineering (2007) uses an assumption of $95 \%$ availability. REPower turbines have shown (in limited lifetimes to date) a very high level of availability, from 94\% to $97 \%{ }^{10}$ and Siemens $3.6 \mathrm{MW}$ turbines have had $97 \%$ availability at Burbo Bank wind farm in the UK. ${ }^{11}$

Regarding energy losses, EWEA (2009) states that cable array losses are $5-10 \%$, grid losses (infield array heat losses) are $1-3 \%$, etc, downtime is put at $2 \%$, though that is for onshore (should be higher offshore, i.e. 5$10 \%$ from Carbon Trust (2008)). These combined suggest an $11-23 \%$ reduction after calculating the total annual energy achieved. For an HVAC transmission system at $27 \mathrm{~km}$ (exactly the distance of Nordergründe), ESS, Inc. (2004) calculates the grid losses as being $1.5 \%$ at peak load.

\section{A.1.1. Wind costs}

A fully documented description of the cost model is given in the User's Guide for the InVEST Offshore Wind Energy model (Sharp et al, 2014). The online version of the User's Guide includes a permanent link to the press releases used to assemble parameter values for this study.

To validate our cost model and parameters, we simulated the total capital cost of 24 offshore wind farms currently in operation and compared the values against published data on stated total capital costs from http://www.4coffshore.com/ and http://www.lorc.dk/offshorewind-farms-map/statistics. This tests how our component-level model

\footnotetext{
${ }^{9}$ http://enr-ee.com/fileadmin/user_upload/Downloads/Offshore/Rencontres_du_ Havre/session4/Mohr_Goesswein.pdf.

10 http://www.renewable-energy-sources.com/2010/06/21/repower-offshore-windturbines-at-thornton-bank-and-alpha-ventus-achieve-first-class-operational-results/.

11 http://www.wirralglobe.co.uk/news/4687615.EXCLUSIVE_Burbo_Bank_wind_farm_ off_Wirral_shore_out_of_action_for_four_weeks_after_cabling_failure/.
}

Project Cost (2012 \$US millions)

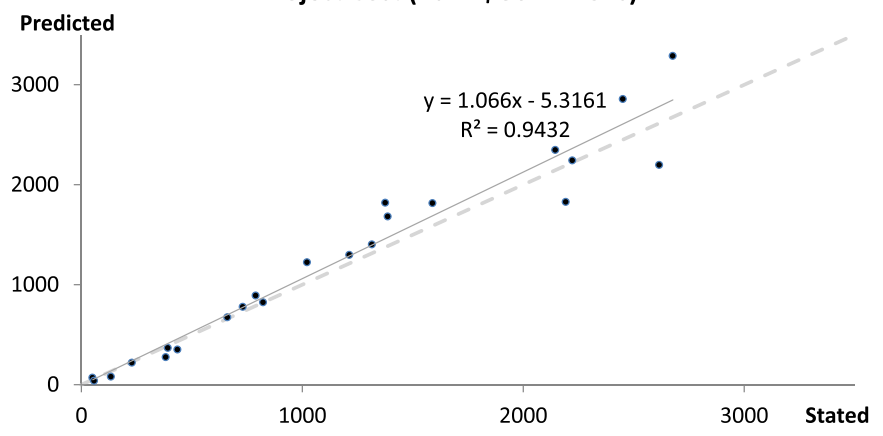

Figure A1. Capital cost validation for operational offshore wind farms.

fares when all costs are aggregated versus independent data on stated total capital costs, giving a measure of how accurate our model is at the farm level. Using data for 3.6 MW and 5.0 MW farms (those employed in this study), we found a very tight correlation between predicted and stated costs as expressed in US\$ (Fig. A1).

\section{A.1.2. Wind farm layout}

A 7x7xrotor dia. min rule for turbine spacing (AWS Truewind, 2010) yields similar results for both the 3.6 turbine and 5.0 turbines (750$880 \mathrm{~m}$, smallest to largest options), and since Nordergründe uses $1000 \mathrm{~m}$ (approx.) spacing, we take that as the common spacing across projects. This implies that the plot sizes will remain constant across alternatives. For a buffer, we add 7 times the rotor diameter around the farm layout.

\section{A.2. Mussels}

This analysis uses scenario 1 in Buck et al. (2010), production of consumption mussels with investment into a new vessel.

Most of the cost data for mussels is taken directly from Buck et al. (2010) and is transformed where necessary to fit model specification. Also, the focus is on mussel growth for consumption, as it has been shown to be the more profitable option compared to growing seed mussels. Like wind energy, the expected output per unit is constant by design. All costs have been inflated from March $30^{\text {th }}, 2010$ to March $30^{\text {th }}$, 2012.

Since our time horizon is longer than the 4 years of Buck et al. (2010), we have had to address a few issues. The useful life of most capital expenditures is less than the 20 year horizon we are using, so the below gives our new assumptions:

- All plot-related infrastructure has a useful life of 4 years, in contrast to the longer life for some items (such as buoys, stones, and anchors)

- The motor(s) are rebuilt in year 10 , but not in year 20, leaving no residual value to the vessels

- The land facilities' useful life is given as 15 years. To get through year 20 we are requiring an annual maintenance fee starting in year 16 equal to the straightline depreciation value. This is discounted back for present value purposes.

- Given the production schedule, there is a harvest (of half the plots) that could be had in year 21 . We assume this is not realized as it is outside the production horizon and the useful life of most of the equipment.

- Repairs/maintenance and miscellaneous costs from Buck et al (2010), Table 2, are given as $10 \%$ and $5 \%$ of the depreciated value of the assets over 4 years. We lump this together as O\&M in our Table 2, and turn $15 \%$ over 4 years into $3.75 \%$ of CAPEX expenditures per year for the lifetime of the farm. This cost category is independent of fuel and labor costs for O\&M. 
Regarding the number of plots, given that the design of any given windfarm is likely to be optimized for wind, rather than aquaculture production, it is unlikely that an aquaculturist could expect the maximum 63 plots on a wind farm of 80 turbines. In a farm with 18 turbines Buck et al (2010) used 4 plots (of a potential 6). A similar scale will be used in this approach, with 16 plots (out of a maximum of 63) in operation. Since we have no data to support quantitative differences in returns to scale, the variation in scaling is simply a proportional adjustment anyway.

We adopt the size used by Buck et al (2010). Their study site had $1000 \mathrm{~m}$ average distance in all directions between turbines. Alpha Ventus has between $760 \mathrm{~m}$ and $840 \mathrm{~m}$ on a smaller farm. The optimal configuration and layout of wind farms on the open ocean is a work in progress still (Samorani, 2010). The resultant size of a plot is 121 acres.

According to Kite-Powell et al. (2003) one vessel is capable of servicing a field of 300 longlines. There are 71 longlines per plot, so 4 plots are serviceable by one vessel. In a 16 plot context, 4 vessels would be necessary.

Pg. 10 of Buck et al. (2010) lists the sourcing backing the biomass per meter of collector, and puts it at $10-15 \mathrm{~kg}$.

We collected prices for aquacultured mussels in Germany from the FAO's Fishstat database. This supplies both value and quantity information from 1984 to 2012, from which we imputed annual mean prices per kilogram over that span. A linear regression was fit to the data to estimate prices and price uncertainty going forward through our simulated 20 year farm lifespan. The $\mathrm{R}^{2}$ of the regression was .47 , and it revealed a linear price increase of .048€ per year and a standard deviation for the price prediction of .44€. This is acknowledged as a very rough approximation of prices, as FAO data is not authoritative and a market study beyond the considerations of Nguyen (2012) would be advised for any firm that is considering large production volumes.

\section{Additional Appendix References}

AWS Truewind. 2010. New York's Offshore Wind Energy Development Potential in the Great Lakes. Feasibility Study for New York State Energy Research and Development Authority.

Carbon Trust. 2008. Offshore Wind Power: Big Challenge, Big Opportunity. Report on behalf of the Government of the United Kingdom.

ESS, Inc. 2004. "Transmission Issues for Offshore Windfarms." Appendix 3-C of Draft Environmental Impact Statement, U.S. Army Corps of Engineers.

EWEA. 2009. The Economics of Wind Energy. EWEA Report, ed: S. Krohn.

Kite-Powell, H.L., P. Hoagland, D. Jin, and K. Murray. 2003. Economics of open-ocean growout of shellfish in New England: Sea scallops and blue mussels. Pages 293-306 in Bridger, C. and B. Costa-Pierce, eds., Open-Ocean Aquaculture: From Research to Reality. Charleston, SC: World Aquaculture Society.

Offshore Design Engineering. 2007. Study of the Costs of Offshore Wind Generation. Technical Report for the UK Renewables Advisory Board and the Department of Trade and Industry. URN Number 07/779.

Samorani, Michele. 2010. The Windfarm Layout Optimization Problem. Leeds School of Business Research Paper Series, University of Colorado at Boulder.

Sawyer, S. 2008. "Offshore Wind: Pioneering a New Industry", Marine Law Symposium, Roger Williams University School of Law, Bristol, Rhode Island.

Sharp, R., Tallis, H.T., Ricketts, T., Guerry, A.D., Wood, S.A., ChaplinKramer, R., Nelson, E., Ennaanay, D., Wolny, S., Olwero, N., Vigerstol, K., Pennington, D., Mendoza, G., Aukema, J., Foster, J., Forrest, J., Cameron, D., Arkema, K., Lonsdorf, E., Kennedy, C., Verutes, G., Kim, C.K., Guannel, G., Papenfus, M., Toft, J., Marsik, M., Bernhardt, J., Griffin, R., Glowinski, K., Chaumont, N., Perelman, A., Lacayo, M. Mandle, L., Griffin, R., and
Hamel, P. 2014. InVEST tip User's Guide. The Natural Capital Project, Stanford.

\section{Appendix A}

Supplementary data to this article can be found online at http://dx. doi.org/10.1016/j.aquaculture.2014.10.035.

\section{References}

Boccard, N., 2010. Economic properties of wind power: a European assessment. Energy Policy 38, 3232-3244.

Buck, B., 2007a. Experimental trials on the feasibility of offshore seed production of the mussels Mytilus edulis in the German Bight: Installation, technical requirements and environmental conditions. Helgol. Mar. Res. 61, 87-101-87-101.

Buck, B., 2007b. Farming in a high energy environment: potentials and constraints of sustainable offshore aquaculture in the German Bight (North Sea). Rep. Polar Mar. Res. 543, 235.

Buck, B., Buchholz, C., 2004. The offshore-ring: a new system design for the open ocean aquaculture of macroalgae. J. Appl. Phycol. 16 (355-268).

Buck, B., Buchholz, C., 2005. Response of offshore cultivated Laminaria saccharina to hydrodynamic forcing in the North Sea. Aquaculture 250, 95-122-95-122.

Buck, B., Krause, G., 2012. Integration of aquaculture and renewable energy systems. In: Meyers, Robert A. (Ed.), Encyclopaedia of Sustainability Science and Technology vol 1. Springer Science + Business Media LLC, pp. 511-533 (Chapter No. 180).

Buck, B., Krause, G., Rosenthal, H., 2004. Extensive open ocean aquaculture development within windfarms in Germany: The prospect of offshore co-management and legal constraints. Ocean Coast. Manag. 47, 95-122.

Buck, B., Krause, G., Michler-Cieluch, T., Brenner, M., Buchholz, C., Busch, J., Fisch, R., Geisen, M., Zielinski, O., 2008. Meeting the quest for spatial efficiency: progress and prospects of extensive aquaculture within offshore wind farms. Helgol. Mar. Res. 62, 269-281.

Buck, B., Ebeling, M., Michler-Cieluch, T., 2010. Mussel cultivation as a co-use in offshore wind farms: Potential and economic feasibility. Aquac. Econ. Manag. 14, 255-281.

Bundesamt fur Seeschifffahrt und Hydrographie (BSH)., 2009. Maritime spatial plan: environmental report. http://www.bsh.de/en/Marine_uses/Spatial_Planning_in_the_ German_EEZ/index.jsp.

Chambers, M.D., 1998. Potential Offshore Cage Culture Utilizing Oil and Gas Platforms in the Gulf of Mexico. Open Ocean Aquaculture: Chartering the Future of Ocean Farming. UNIHI-Seagrant-CP-98-08, Maui, University of Hawaii Sea Grant College Program, Maui, Hawaii, pp. 77-87.

Christie, N., Smyth, K., Barnes, R., Elliott, M., 2014. Co-location of activities and designations: A means of solving or creating problems in marine spatial planning? Mar. Policy 43, 254-261.

Cicin-Sain, B., Bunsick, S., Corbin, J., DeVoe, M., Eichenberg, T., Ewart, J., Firestone, J. Fletcher, K., Halvorson, H., MacDonald, T., Rayburn, R., Rheault, R., Thorne-Miller, B. Didden, J., Blaydes, M., 2005. Recommendations for an Operational Framework for Offshore Aquaculture in U.S. Federal Waters. Technical Report. Gerard J. Mangone Center for Marine Policy. University of Delaware.

Douvere, F., 2008. The importance of marine spatial planning in advancing ecosystembased sea use management. Mar. Policy 32, 762-771.

Dvorak, M., Archer, C., Jacobsen, M., 2010. California offshore wind energy potential. Renew. Energy 35, 1244-1254.

European Commission, 2011. Maritime spatial planning in the EU - Achievements and future developments. Publications Office of the European Union, Luxembourg.

European Wind Energy Association (EWEA)., 2013. The European offshore wind industry key trends and statistics, 2012Accessed at http://www.ewea.org/fileadmin/files/ library/publications/statistics/European_offshore_statistics_2012.pdf.

Global Wind Energy Council (GWEC), 2013. Global Wind Statistics, 2012Accessed at http://www.gwec.net/wp-content/uploads/2013/02/GWEC-PRstats-2012_english. pdf.

Heitt, R.L., Milon, J.W., 2002. Economic Impact of Recreational Fishing and Diving Associated with Offshore Oil and Gas Structures in the Gulf of Mexico: Final report. OCS Study MMS 2002-010. U.S. Dept. of the Interior, Minerals Management Service, Gulf of Mexico OCS Region, New Orleans.

Hoagland, P., Jin, D., Kite-Powell, H., 2003. The optimal allocation of ocean space: aquaculture and wild-harvest fisheries. Mar. Resour. Econ. 18, 129-147.

Jorant, C., 2011. The implications of Fukushima: the European perspective. Bull. At. Sci. 67, 14-17.

Kaiser, M., Yu, Y., Snyder, B., 2010. Economic feasibility of using offshore oil and gas structures in the Gulf of Mexico for platform-based aquaculture. Mar. Policy 34, 699-707.

Kaiser, M., Snyder, B., Yu, Y., 2011. A review of the feasibility, costs, and benefits of platform-based open ocean aquaculture in the Gulf of Mexico. Ocean Coast. Manag. 54, 721-730.

Kareiva, P., Tallis, H., Ricketts, T., Daily, G., Polasky, S., 2011. Natural Capital: Theory and Practice of Mapping Ecosystem Services. Oxford University Press.

Karyotakis, A., 2011. On the optimization of operations and maintenance strategies for offshore wind farms. Dissertation submitted to the Department of Mechanical Engineering. University College of London.

Kirkley, J., 2008. The potential economic ramifications of offshore aquaculture. In: Program, N.A. (Ed.), Offshore Aquaculture in the United States: Economic Considerations, Implications and Opportunities. NOAA, Silver Spring, MD. 
Klinger, D., Naylor, R., 2012. Searching for solutions in aquaculture: charting a sustainable course. Annu. Rev. Environ. Resour. 37, 247-276.

Krause, G., Griffin, R., Buck, B., 2011. Perceived concerns and advocated organizational structures of ownership supporting offshore wind farm - mariculture integration. In: Krause, G. (Ed.), From Turbines to Wind Farms - Technical Requirements and Spin-off Products. InTech Publishing, Vienna, Austria, pp. 203-218.

Kwak, Y., Ingall, L., 2007. Exploring Monte Carlo simulation applications for project management. Risk Manag. 9, 44-57.

Ladenburg, J., Lutzeyer, S., 2012. The economics of visual disamenity reductions of offshore wind farms: Review and suggestions from an emerging field. Renew. Sust. Energ. Rev. 16, 6793-6802.

Levitt, A., Kempton, W., Smith, A., Musial, W., Firestone, J., 2011. Pricing offshore wind energy. Energy Policy 39, 6408-6421.

Masters, G., 2004. Renewable and Efficient Electric Power Systems. John Wiley \& Sons, Hoboken, New Jersey.

Midget, R.J., 1994. The Development of Marine Fish Cage Culture in Association with Offshore Oil Rigs. Culture of High Value Marine Fishes in Asia and the United States. 241-248, (Honolulu).

Munoz, J., Contreras, J., Caamano, J., Correia, P., 2009. Risk assessment of wind power generation project investments based on real options. Proceedings of IEEE PowerTech (Budapest, Romania).

Negra, N., Todorovic, J., Ackermann, T, 2006. Loss evaluation of HVAC and HVDC transmission solutions for large offshore wind farms. Electr. Power Syst. Res. 76, 916-927.

Nguyen, T., 2012. An inverse almost ideal demand system for mussels in Europe. Mar. Resour. Econ. 27, 149-164.

Olsen, S.B., McCann, J.H., Fugate, G., 2014. The State of Rhode Island's pioneering marine spatial plan. Mar. Policy 45, 26-38.
Pogoda, B., Buck, B., Hagen, W., 2011. Growth performance and condition of oysters (Crassostrea gigas and Ostrea edulis) farmed in an offshore environment. Aquaculture 319, 484-492.

Pogoda, B., Jungblut, S., Buck, B., Hagen, W., 2012. Parasitic infestations of copepods in oysters and mussels: differences between nearshore wild banks and an offshore cultivation site in the German Bight. J. Appl. Ichthyol. 28, 756-765.

Pogoda, P., Buck, B., Saborowski, R., Hagen, W., 2013. Biochemical and elemental composition of the offshore cultivated oysters Ostrea edulis and Crassostrea gigas. Aquaculture 319, 53-60.

Rademakers, L., Braam, H., 2003. O\&M aspects of the $500 \mathrm{MW}$ offshore wind farm at NL7. DOWEC report 10090 rev 1 Accessed at http://www.ecn.nl/fileadmin/ecn/units/wind/ docs/dowec/10080_002.pdf.

Stoutenburg, E., Jacobson, M., 2011. Reducing offshore transmission requirements by combining offshore wind and wave farms. IEEE J. Ocean. Eng. 36, 552-561.

Tallis, H., et al., 2011. New metrics for managing and sustaining the ocean's bounty. Mar. Policy 36, 303-306.

Valderrama, D., Engle, C., 2001. Risk analysis of shrimp farming in Honduras. Aquac. Econ. Manag. 5, 49-68.

Ventus, Alpha, 2010. The Building of an Offshore Wind Farm. Deutsche Offshore-Testfeld und Infrastruktur GmbH \& Co. KG. Funded by Federal Maritime and Hydrographic Agency, (53 pp).

Weaver, T., 2012. Financial appraisal of operational offshore wind energy projects. Renew. Sust. Energ. Rev. 16, 5110-5120.

Wilson, C.A., Stanley, D., 1998. Constraints of Operating on Petroleum Platforms as it Relates to Mariculture: Lessons from Research. Joining Forces With Industry - Open Ocean Aquaculture. Texas Sea Grant College Program, Chorpus Christi, Texas, p. 60.

Yescombe, E., 2002. Principles of Project Finance. Academic Press, San Diego, CA, USA. 